\title{
Valorization of Microalgae Biomass by Its Use for the Removal of Paracetamol from Contaminated Water
}

\author{
Carla Escapa ${ }^{1}$, Ricardo N. Coimbra ${ }^{1}$, Cristina Nuevo ${ }^{1}$, Samuel Vega ${ }^{1}$, Sergio Paniagua ${ }^{1}$, \\ Ana I. García ${ }^{1}$, Luis F. Calvo ${ }^{1, *}$ and Marta Otero ${ }^{1,2, *}$ \\ 1 Department of Applied Chemistry and Physics, Institute of Environment, Natural Resources and \\ Biodiversity (IMARENABIO), Universidad de León, León 24071, Spain; carla.escapa@unileon.es (C.E.); \\ rdes@unileon.es (R.N.C.); cnuevt00@estudiantes.unileon.es (C.N.); svegae00@estudiantes.unileon.es (S.V.); \\ sergio.paniagua@unileon.es (S.P.); ana.garcia@unileon.es (A.I.G.) \\ 2 Centre for Environmental and Marine Studies (CESAM), Department of Environment and Planning, \\ University of Aveiro, Aveiro 3810-193, Portugal \\ * Correspondence: lfcalp@unileon.es (L.F.C.); marta.otero@ua.pt (M.O.); Tel.: +34-98-729-1844 (L.F.C.)
}

Academic Editor: José Manuel Poyatos

Received: 17 March 2017; Accepted: 26 April 2017; Published: 28 April 2017

\begin{abstract}
Microalgae are aquatic photosynthetic prokaryotic or eukaryotic microorganisms which cultivation for the fixation of $\mathrm{CO}_{2}$ and the production of biofuels has received large attention. However, the sustainable development of an algal biorefinery is still a challenge. In this context, the valorization of microalgae biomass for a wastewater adsorptive treatment may be an option to explore. Recently, the presence of emerging contaminants (ECs) in natural waters and the associated risks have led to a great concern, especially in the case of pharmaceuticals. In the present work, the elimination of paracetamol from water by biosorption onto microalgae, namely Synechocystis sp., has been studied. Kinetic and equilibrium parameters have been determined and compared with those obtained when using a commercial activated carbon under the same experimental conditions. Although the adsorption kinetics are very similar onto both materials, at the equilibrium, the Langmuir maximum capacity of the activated carbon $\left(278 \mathrm{mg} \mathrm{g}^{-1}\right)$ is five times higher than that of Synechocystis sp. $\left(53 \mathrm{mg} \mathrm{g}^{-1}\right)$. In any case, it must be considered that the utilization of microalgae may be considered an environmentally friendly process with important associated savings.
\end{abstract}

Keywords: adsorption; emerging contaminants (ECs); wastewater treatment

\section{Introduction}

The worldwide energy crisis and global warming have both caused an increase in the research on the production of renewable energies [1]. The Kyoto Protocol committed the signatory countries to reduce the emission of greenhouse gases, so the production of third generation biofuels from photosynthetic microorganisms, such as microalgae and cyanobacteria, has stirred up considerable attention due to their $\mathrm{CO}_{2}$ fixation capacity $[2,3]$.

Nowadays, only $5 \mathrm{kt} /$ year of microalgal biomass are produced with production costs of $18.527 € / t[4]$, a reduction up to $296 € / t$ being needed to reach a competitive price in the biofuels market [5]. Furthermore, to substitute the consumption of biofuels in Europe by microalgal biodiesel, 9.25 millions of hectares (approximately the surface of Portugal) with a productivity of 40,000 L/ha/year [6] are needed. On the other hand, huge amounts of phosphorus and nitrogen are necessary for the culture of microalga, which reduces the sustainability of the process because of both their high price as a pure chemical product and their availability [7]. 
The above said has led to conducting research on the use of polluted effluents, such as municipal wastewater, as a source of nutrients for the production of microalgae and the reduction of associated costs. Furthermore, this utilization has the advantage of the enhanced depuration of these polluted waters [8,9]. Using microalgae for wastewater remediation has been raised as a win-win paradigm within environmental biorefinery [10]. Among the several applications in wastewater treatment, biosorption has been defined as the passive uptake of pollutants by microalgal non-living biomass. In this sense, although most of the biosorption studies in the scientific literature deal with the removal of heavy metals [11], the adsorption capacity of organic pollutants by microalgae has also been proved [12]. Likewise, apart from their capacity of adsorption, low cost, and a huge availability, the utilization as biosorbent of the residual microalgal biomass after the extraction of the lipid content could mean a way to increase the economic viability of the biodiesel production from microalgae [13].

Currently, large concern exists about the presence of the so called emerging contaminants (ECs) in the environment. The presence of ECs in the environment is not regulated by legislation, but it is known that it may be a threat for ecosystems and human health [14]. These ECs include a large variety of compounds such as pharmaceuticals, personal care products, surfactants, flame retardants, antiseptics, etc. The way these pollutants enter the aquatic environment depends on their utilization pattern. In the case of the ECs from human consumption and/or excretion, such as pharmaceuticals, the main source are the municipal wastewater treatment plants (WWTP) [14] since they have been designed just for the reduction of the legislated parameters.

The environmental concern of ECs, namely on pharmaceuticals, has led to the recent consideration by European regulations within the Water Framework Directive (2000/60/EC) (WFD). Three pharmaceuticals (diclofenac, 7-beta-estradiol (E2) and 17-alpha-ethinylestradiol (EE2)) were proposed to be included the list of priority substances by the Commission proposal of 31 January 2012. However, by the Directive 2013/39/EU, these pollutants were finally included in the watch list of substances to be monitored in all member states to support future reviews of the priority substances list [15]. Therefore, since legal limits about pharmaceuticals concentration in the effluents of the WWTPs are expected to be established in the near future, investigation of their removal from waters is essential. For this purpose, adsorption treatments are promissory, since they are efficient and besides, they do not imply the transformation of the ECs in different products, which may have more dangerous effects than the original compounds. However, activated carbon, which is the most largely used adsorbent for industrial wastewater treatment, has a quite high price for its implementation at the majority of municipal WWTPs. In this case, and as above highlighted, the utilization of microalgae as biosorbent in wastewater treatment could be an environmentally friendly and economically sustainable option.

Sorption by microalgae has been pointed out as a key process in the removal of antibiotics in high-rate algal ponds (HRAPs) [16,17]. On the other hand, when studying the removal of 28 different ECs in HRAPs, Matamoros et al. [18] found that sorption was relevant for the removal of hydrophobic compounds, while other ECs, such as paracetamol, were mostly removed by biodegradation. The removal of pharmaceuticals, including paracetamol, by the microalgae Chlorella sorokiniana was studied by de Wilt et al. [19] in batch experiments, who observed that sorption to algal biomass accounted for less than $20 \%$ of the removal. However, to the best of our knowledge the biosorption of pharmaceuticals, as the passive uptake of such pollutants by non-living microalgal biomass, has not been assessed in the literature. Therefore, the aim of this work was to study the potential of a blue-green microalgae, Synechocystis sp., to be used as a biosorbent for the removal of pharmaceuticals from contaminated water. Paracetamol has been selected as target EC in this study, since it belongs to the group of anti-inflammatory analgesics, and is one of the most frequently found pharmaceuticals in wastewater. 


\section{Material and Methods}

\subsection{Microorganism and Culture Media}

The strain of the cyanobacteria Synechocystis sp. used in the research was isolated and selected from natural and industrial surroundings of the province of Leon (Spain) [20].

The inoculum was maintained in $250 \mathrm{~mL}$ Erlenmeyer flasks in Mann \& Myers culture media [21]. To guarantee an initial concentration of $0.1 \mathrm{~g} \mathrm{~L}^{-1}$ in the experimental phase, the scale-up to $1 \mathrm{~L}$ bubbling column photobioreactors was made. The growth conditions were maintained at controlled temperature $\left(27-30{ }^{\circ} \mathrm{C}\right), \mathrm{pH}(7.5)$, aeration $(0.3 \mathrm{v} / \mathrm{v} / \mathrm{min})$, photoperiod $(12: 12)$, and irradiance $\left(650 \mu \mathrm{E} \mathrm{m}^{-2} \mathrm{~s}^{-1}\right)$.

\subsection{Photobioreactor and Culture Conditions}

The culture was grown in bubbling column photobioreactors $(0.0875 \mathrm{~m}$ of diameter, $1.7 \mathrm{~m}$ of height and $10 \mathrm{~L}$ of capacity) with an operation volume of $9 \mathrm{~L}$.

The assays were conducted in vegetal culture chambers under stable operation conditions: a temperature of $27-30{ }^{\circ} \mathrm{C}$, a 16:8 photoperiod of light:darkness and irradiance of $650 \mu \mathrm{E} \mathrm{m} \mathrm{m}^{-2} \mathrm{~s}^{-1}$. The culture was aerated with $0.3 \mathrm{v} / \mathrm{v} / \mathrm{min}$ filtered air $(0.22 \mu \mathrm{m})$. The $\mathrm{pH}$ was maintained at 7.5 and controlled by the injection of $\mathrm{CO}_{2}$ "by demand" with a $7 \%$ of the air flow.

\subsection{Adsorbent Materials}

At the end of the culture of Synechocystis sp., the cellular suspension was centrifuged (7800 rpm, $7 \mathrm{~min}$ ) in order to separate the biomass of the culture media by density gradient. After that, two washing steps with distilled water were done. Then, the biomass was frozen and lyophilized. Before its use as a biosorbent, the lyophilized biomass was ground, homogenized, and sieved to 80 meshes. For comparison purposes, a commercial activated carbon (pulverized GPP-20) was used in this work. Pulverized GPP-20, which was generously provided by Chemviron Carbon (Feluy, Belgium), had a particle diameter of less than $0.18 \mathrm{~mm}$ (mesh 80), an iodine number of $700 \mathrm{mg} \mathrm{g}^{-1}$ and a surface area (Brunauer-Emmett-Teller (BET) $\mathrm{N}_{2}$ adsorption method) of $1000 \mathrm{~m}^{2} \mathrm{~g}^{-1}$.

\subsection{Adsorption Experiments}

Paracetamol (Acetaminophen, $\mathrm{C}_{8} \mathrm{H}_{9} \mathrm{NO}_{2}$ ) was purchased from Sigma-Aldrich (Madrid, Spain) and used for the adsorption experiments.

The adsorption experiments were conducted under batch operation mode following a parallel experimental scheme, which means that one separate reactor was used for each desired time and/or paracetamol initial concentration. The reactors used were Erlenmeyer flasks $(100 \mathrm{~mL})$, with $50 \mathrm{~mL}$ of paracetamol solution that was stirred together with a known mass of adsorbent. For comparison purposes, the same paracetamol concentration was used in the adsorption experiments with microalgae biomass or with activated carbon. A preliminary test was carried out to determine the appropriate range of paracetamol to be used in these experiments. For the here used solution volume and the mass of adsorbent that it was possible to accurate measure, the paracetamol range of concentration used in this work (between 15 and $150 \mathrm{mg} \mathrm{L}^{-1}$ ) was defined by the quantification limit and the adsorption capacity of the adsorbent materials.

After stirring, the adsorbent was separated from the liquid phase. In the case of activated carbon, separation was done by centrifugation. Meanwhile, filtration through Millipore membranes (45 $\mu \mathrm{m}$ pore size) was necessary for the separation of microalgae biomass from the liquid phase. Then, the concentration of paracetamol in the liquid phase was determined by the measurement of the absorbance at a wavelength of $243 \mathrm{~nm}$ using a UV-Visible spectrophotometer (T92+ model, PG Instruments, Leicestershire, UK). 


\subsection{Adsorption Kinetics}

An initial concentration $\left(C_{i}\right)$ of $100 \mathrm{mg} \mathrm{L}^{-1}$ was used in adsorption kinetic experiments in order to find out the equilibrium time $\left(t_{e}\right)$. After stirring during pre-defined times, the residual concentration of paracetamol was determined $\left(C_{t}\right)$ as described above. In the case of Synechocystis sp., $0.05 \mathrm{~g}$ of biomass were used as biosorbent, whereas $0.005 \mathrm{~g}$ of activated carbon were used as adsorbent. Experimental conditions were controlled and kept at $250 \mathrm{rpm}$ stirring and $25 \pm 1{ }^{\circ} \mathrm{C}$ of temperature. The $\mathrm{pH}$ of solutions was not fixed at any initial value neither buffered, but stability in the values was observed along the kinetic experiments $(7.0 \pm 0.5)$.

Three replicates were run for each considered adsorbent and time. In parallel, for each adsorbent, controls and blanks were also run in triplicate. Controls were used to verify that the concentration of paracetamol remained stable throughout the duration of adsorption experiments and consisted of $50 \mathrm{~mL}$ of aqueous solution of paracetamol at the corresponding experimental $C_{i}$. Meanwhile, blanks consisted of $50 \mathrm{~mL}$ of distilled water together with $0.05 \mathrm{~g}$ of microalgal biomass or together with $0.005 \mathrm{~g}$ of activated carbon. Blanks were used as reference for the spectrophotometric determination of the residual paracetamol concentration after stirring.

To determine the residual concentration $\left(C_{t}\right)$, at the end of each prefixed stirring time $(t)$, the absorbance in the filtered (MF Millipore, $0.45 \mu \mathrm{m}$ ) aqueous phase was measured. The amount of paracetamol adsorbed in the adsorbent $\left(q_{t}\right)$ was determined by a mass balance at each time, and in function of the initial paracetamol concentration $\left(C_{i}\right), C_{t}$, the volume of the paracetamol solution $(V)$ and the mass of the adsorbent $\left(m_{a d s}\right)$.

$$
q_{t}=\frac{\left(C_{i}-C_{t}\right)}{m_{a d s}} \times V
$$

Paracetamol adsorption kinetics were analyzed by the determination of the fittings to pseudo-first (Lagergren equation) and pseudo-second order equations. The Equation (2) was obtained by the integration of $q_{e}, q_{t}$ and pseudo-first order kinetic constant $\left(k_{1}\right)$ of the Lagergren equation.

$$
q_{t}=q_{e}\left(1-e^{-k_{1} t}\right)
$$

The Equation (3) was obtained after the integration of the pseudo-second order equation, and it depends on $q_{e}, q_{t}$ and second order kinetic constant $\left(k_{2}\right)$ parameters.

$$
q_{t}=\frac{q_{e}^{2} k_{2} t}{1+k_{2} q_{e} t}
$$

In order to establish the fittings to these equations to kinetic experimental results, non-linear regression was carried out using the software GraphPad Prism (demo, version 6, GraphPad Software, La Jolla, CA, USA).

\subsection{Adsorption Equilibrium}

Once the equilibrium time was determined ( $t_{e}=240 \mathrm{~min}$ ), adsorption equilibrium experiments were conducted in order to determine the adsorption isotherms. These experiments were carried out at different initial paracetamol concentrations $\left(15 \mathrm{mg} \mathrm{L}^{-1} \leq \mathrm{Ci} \leq 150 \mathrm{mg} \mathrm{L}^{-1}\right)$. The solution volume was $50 \mathrm{~mL}$ and the adsorbent mass $\left(m_{a d s}\right)$ was $0.05 \mathrm{~g}$ in the case of Synechocystis sp. and $0.005 \mathrm{~g}$ of activated carbon. All the experiments were run in triplicate in parallel with the corresponding triplicate controls (50 $\mathrm{mL}$ of paracetamol solution at the experimental $C_{i}$ but in the absence of adsorbent) and blanks (50 $\mathrm{mL}$ of distilled water together with the corresponding mass of adsorbent). For each adsorption experiment, the amount of paracetamol adsorbed in the equilibrium $\left(q_{e}\right)$ was determined as a function of the equilibrium concentration $\left(C_{e}\right)$, according to the mass balance in Equation (4). 


$$
q_{e}=\frac{\left(C_{i}-C_{e}\right)}{m_{a d s}} \times V
$$

Aiming to describe the equilibrium isotherms, the fittings of experimental results to Langmuir [22] and Freundlich [23] isotherm models were determined. In the equilibrium, the Langmuir isotherm assumes that the maximum adsorption capacity by an adsorbent corresponds to the saturation of the adsorption sites surface when covered by a monolayer of adsorbate molecules, which do not interact with each other. This model expresses the amount of adsorbed adsorbate depending on the maximum adsorption capacity of the adsorbent material $\left(Q_{m}\right)$, and the Langmuir constant, related to the adsorption energy $\left(K_{L}\right)$

$$
q_{e}=\frac{Q_{m} K_{L} C_{e}}{1+K_{L} C_{e}}
$$

On the other hand, Freundlich proposed an empiric model for the case of heterogeneous surface energies, corresponding to an exponential distribution of the adsorption heats. This model is defined by the Freundlich constant $\left(K_{f}\right)$ and the constant related to the intensity of the adsorption process $(N)$.

$$
q_{e}=K_{f} C_{e}^{\frac{1}{N}}
$$

The fittings of the equilibrium experimental results to Langmuir and Freundlich isotherms were obtained by non-lineal regression using GraphPad Prism.

\section{Results}

The amount of paracetamol adsorbed onto microalgae or activated carbon versus contact time under stirring is shown in Figure 1. For both adsorbents, the amount of adsorbed paracetamol increased with time until becoming stable at the equilibrium, which happened after stirring for $240 \mathrm{~min}$.

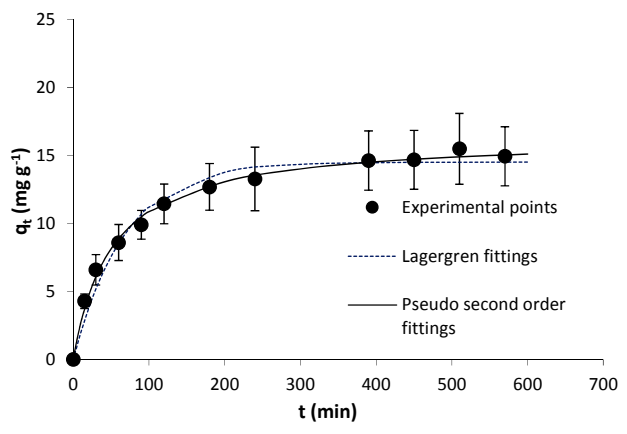

(a)

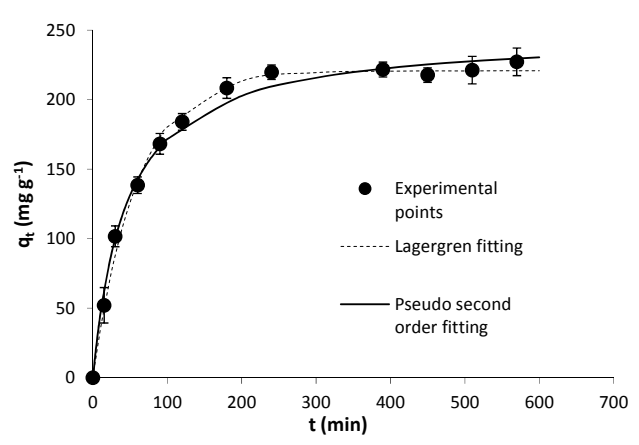

(b)

Figure 1. Kinetic results on the adsorption of paracetamol onto (a) Synechocystis sp.; (b) activated carbon. Experimental results of the adsorbed paracetamol $\left(q_{t}, \mathrm{mg} \mathrm{g}^{-1}\right)$ versus time $(t, \mathrm{~min})$ are represented together with fittings to the Lagergren and pseudo-second order kinetic equations. Note: Error bars stand for standard deviation.

Although adsorption kinetics onto both adsorbents were similar in terms of $t_{e}$, the adsorbed paracetamol at the equilibrium was quite higher in the case of the activated carbon than in the case of microalgae. In Synechocystis sp. kinetic experiments, about $10 \%$ of the initial amount of paracetamol was absorbed at $t_{e}$, while, in the case of commercial activated carbon, about $20 \%$ of the initial amount of paracetamol was adsorbed at this time. From a practical point of view, these results point to the necessity of a larger adsorbent:solution ratio to attain higher percentages of paracetamol removal under the experimental conditions used here.

The fittings of the experimental results to the kinetic models of Lagergren (pseudo first-order) and pseudo second-order are shown together with the experimental results in Figure 1. The kinetic parameters derived from these results are shown in Table 1. As may be seen, both kinetic equations 
fitted results with similar $r^{2}$ and Sxy and both $k_{1}$ and $k_{2}$ indicated a faster adsorption rate onto Synechocystis sp.

Table 1. Parameters from the experimental results fittings to the kinetic equations (pseudo first-order (Lagergren equation) and pseudo second-order equations) and equilibrium isotherms (Langmuir and Freundlich isotherms).

\begin{tabular}{|c|c|c|c|}
\hline Kinetic Equations & Parameter & Synechocystis sp. & Activated Carbon \\
\hline \multirow{4}{*}{ Pseudo $1^{\text {st }}$ order } & $k_{1}\left(\min ^{-1}\right)$ & $0.014 \pm 0.002$ & $0.017 \pm 0.001$ \\
\hline & $q_{e}\left(\mathrm{mg} \mathrm{g}^{-1}\right)$ & $14.51 \pm 0.39$ & $220.8 \pm 2.6$ \\
\hline & $r^{2}$ & 0.97 & 0.99 \\
\hline & $S_{x y}$ & 0.9 & 5.9 \\
\hline \multirow{4}{*}{ Pseudo $2^{\text {nd }}$ order } & $k_{2}\left(\mathrm{mg} \mathrm{g}^{-1} \min ^{-1}\right)$ & $0.0012 \pm 0.0001$ & $90 \cdot 10^{-6} \pm 8 \cdot 10^{-6}$ \\
\hline & $q_{e}\left(\mathrm{mg} \mathrm{g}^{-1}\right)$ & $16.38 \pm 0.26$ & $247.5 \pm 4.5$ \\
\hline & $r^{2}$ & 0.99 & 0.99 \\
\hline & $S_{x y}$ & 0.4 & 6.8 \\
\hline Equilibrium Isotherms & Parameter & Synechocystis sp. & Activated Carbon \\
\hline \multirow{4}{*}{ Freundlich } & $K_{F}\left(\mathrm{mg} \mathrm{g}^{-1}\left(\mathrm{mg} \mathrm{L}^{-1}\right)^{-N}\right)$ & $0.63 \pm 0.06$ & $40.33 \pm 12.21$ \\
\hline & N & $1.36 \pm 0.04$ & $2.7 \pm 0.5$ \\
\hline & $r^{2}$ & 1.00 & 0.90 \\
\hline & $S_{x y}$ & 0.4 & 23.9 \\
\hline \multirow{4}{*}{ Langmuir } & $Q_{\max }\left(\mathrm{mg} \mathrm{g}^{-1}\right)$ & $52.8 \pm 6.8$ & $278.3 \pm 11.3$ \\
\hline & $K_{L}\left(\mathrm{~L} \mathrm{mg}^{-1}\right)$ & $0.0055 \pm 0.0010$ & $0.044 \pm 0.006$ \\
\hline & $r^{2}$ & 0.99 & 0.99 \\
\hline & $S_{x y}$ & 0.6 & 9.1 \\
\hline
\end{tabular}

The paracetamol adsorption equilibrium isotherms using Synechocystis sp. and activated carbon as adsorbents are shown in Figure 2.

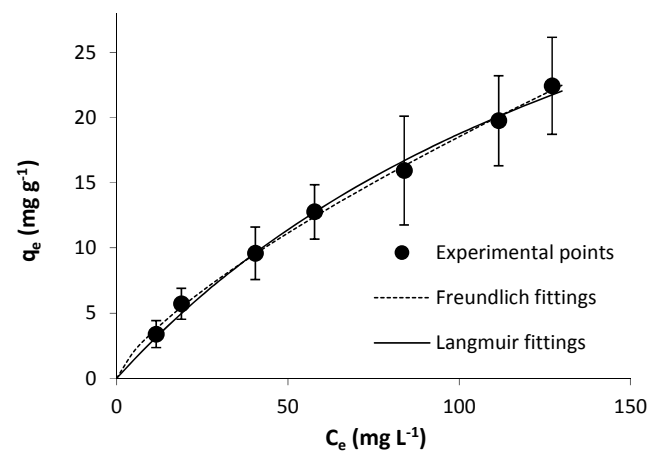

(a)

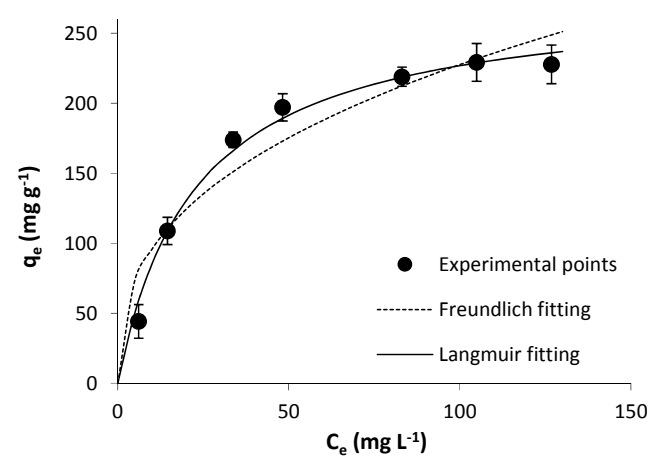

(b)

Figure 2. Equilibrium results on the adsorption of paracetamol onto (a) Synechocystis sp.; (b) activated carbon. Equilibrium experimental results of the adsorbed paracetamol $\left(q_{e}, \mathrm{mg} \mathrm{g}^{-1}\right)$ versus paracetamol concentration in the liquid phase $\left(C_{e}, \mathrm{mg} \mathrm{L}^{-1}\right)$ are represented together with fittings to the Langmuir and Freundlich equilibrium isotherm models. Note: Error bars stand for standard deviation.

Although the isotherms show a similar trend, the difference between the adsorption capacities of both adsorbent materials is remarkable. The fittings of experimental results to the Langmuir and Freundlich adsorption isotherms are shown in Figure 2 together with the experimental results. As it may be seen, the Langmuir isotherm well described the adsorption equilibrium of paracetamol onto the commercial activated carbon, which points to the homogeneity of the activated carbon surface. However, in the case of Synechocystis sp., although the quality of Langmuir and Freundlich fittings 
were quite similar, the Freunlich isotherm described experimental results slightly better, pointing to a certain surface heterogeneity as compared with activated carbon.

Fitted parameters for the Langmuir and Freundlich isotherms are shown in Table 1. In the case of Langmuir, $Q_{\max }$ indicates the maximun adsorption capacity of the adsorbent material corresponding to a monolayer coverage by the adsorbate (paracetamol, in this study); meanwhile, $K_{L}$ is related to the binding energy, the higher the $K_{L}$, the largest affinity of the adsorbent for the adsorbate. The obtained $Q_{\max }$ values indicated that the commercial activated carbon poses a five times larger adsorption capacity $\left(278 \mathrm{mg} \mathrm{g}^{-1}\right)$ than the microalgae biomass $\left(53 \mathrm{mg} \mathrm{g}^{-1}\right)$. Moreover, the $K_{L}$ constant corresponding to the commercial activated carbon was one order of magnitude higher than that of Synechocystis sp., pointing to the lower affinity of the latter for paracetamol.

In the Freundlich isotherm model, $K_{f}$ and $N$ parameters are empirical constants related to the adsorption capacity of the adsorbent and the adsorption intensity, respectively. $K_{f}$ high values indicate a high adsorption capacity and, in this study, the $K_{f}$ corresponding to the activated carbon was significantly higher than that of microalgae. Thus, the activated carbon displayed a $K_{f}$ of $40\left[\left(\mathrm{mg} \mathrm{L}^{1 / N}\right) /\left(\mathrm{g} \mathrm{mg}^{1 / N}\right)\right]$ while the microalgae had a value of $0.6\left[\left(\mathrm{mg} \mathrm{L}^{1 / N}\right) /\left(\mathrm{g} \mathrm{mg}^{1 / N}\right)\right]$. In any case, $N>1$ for both adsorbents, which points to favorable adsorption of paracetamol.

Research carried out on the adsorption of paracetamol from water using alternative adsorbents is still scarce. Crop residues [24] and pyrolysed pulp mill sludge [25] have been used for the adsorption of paracetamol from water and Langmuir fittings of equilibrium results revealed $Q_{\max }$ values of $218 \mathrm{mg} \mathrm{g}^{-1}$ and $12 \mathrm{mg} \mathrm{g}^{-1}$, respectively. Therefore, the maximum capacity of crop residues is larger than that obtained in this work when using microalgae $\left(Q_{\max }=53 \mathrm{mg} \mathrm{g}^{-1}\right)$, but similar to that of the here used activated carbon $\left(Q_{\max }=278 \mathrm{mg} \mathrm{g}^{-1}\right)$. The Freundlich fitted constant ( $N$ value) determined for the adsorption equilibrium onto crop residues [24] was 1.3, which is lower than the value obtained for the activated carbon in this work but almost the same to that obtained for microalgae. On the other hand, pyrolyzed pulp mill sludge [25] showed a lower $Q_{\max }$ than both the microalgae and activated carbon used here.

Regarding the adsorption of paracetamol from aqueous solution onto activated carbons, some studies have been carried out using materials from different companies [26]. Equilibrium results from these studies and the corresponding fittings provided $Q_{\max }$ between 163 and $323 \mathrm{mg} \mathrm{g}^{-1}$, which comprises the capacity of the here used activated carbon.

It must be here highlighted that the separation of microalgae biomass from treated water is a key issue for the practical utilization of microalgae in wastewater treatment. In this study, at the end of adsorption experiments, separation of microalgae biomass was carried out by filtration. However, this is not feasible at a real scale, at which, flocculation-coagulation would be used for the separation of microalgae from the liquid phase. As described elsewhere $[27,28]$ different flocculants may be used for this purpose.

\section{Conclusions}

In this work, and for the very first time, the biosorption of paracetamol from water onto microalgae, namely onto Synechocystis sp., has been determined. Results were compared with the adsorption of this pharmaceutical onto a commercial activated carbon under identical experimental conditions. The kinetic experimental results have been properly described by the Lagergren and the pseudo second kinetic equations, and the equilibrium time was $240 \mathrm{~min}$ for both adsorbent materials. Regarding the equilibrium experimental results on activated carbon, they were better described by the Langmuir than by the Freundlich isotherm, as for the surface homogeneity of this commercial adsorbent. Meanwhile, both isotherm models described equilibrium results in the case of biosorption onto Synechocystis sp. A comparison of the Langmuir maximum adsorption capacities for paracetamol showed that the capacity of the commercial activated carbon $\left(278 \mathrm{mg} \mathrm{g}^{-1}\right)$ is around five times higher than that of the microalgae used in this work $\left(53 \mathrm{mg} \mathrm{g}^{-1}\right)$. In any case, this preliminary study points to the potential of 
microalgae for removing pharmaceuticals from wastewater by biosorption, by which its application may increase the sustainability of their use as second generation biofuels and/or for $\mathrm{CO}_{2}$ fixation.

Acknowledgments: Authors thank University of León for funding given to MICROTRAT (project UXXI2016/00128). Carla Escapa and Sergio Paniagua acknowledge the Spanish Ministry of Educations, Culture and Sports for their PhD fellowships (FPU12/03073 and FPU14/05846, respectively).

Author Contributions: Marta Otero, Luis F. Calvo and Ana I. García conceived and designed the experiments. Carla Escapa, Ricardo N. Coimbra, Cristina Nuevo and Samuel Vega performed the experiments. Marta Otero and Ricardo N. Coimbra carried out the modeling work and data analysis. Carla Escapa, Sergio Paniagua, Cristina Nuevo and Samuel Vega prepared the first draft of the manuscript. All authors produced and approved the final version of the manuscript.

Conflicts of Interest: The authors declare no conflict of interest.

\section{References}

1. Demirbas, A. Biodiesel from oilgae, biofixation of carbon dioxide by microalgae: A solution to pollution problems. Appl. Energ. 2011, 88, 3541-3547. [CrossRef]

2. Martínez, L.; Redondas, V.; García, A.-I.; Morán, A. Optimization of growth operational conditions for $\mathrm{CO}_{2}$ biofixation by native Synechocystis sp. J. Chem. Technol. Biotechnol. 2011, 86, 681-690.

3. González-López, C.V.; Acién Fernández, F.G.; Fernández-Sevilla, J.M.; Sánchez Fernández, J.F.; Molina Grima, E. Development of a process for efficient use of $\mathrm{CO}_{2}$ from flue gases in the production of photosynthetic microorganisms. Biotechnol. Bioeng. 2012, 109, 1637-1650.

4. Pulz, O.; Gross, W. Valuable products from biotechnology of microalgae. Appl. Microbiol. Biot. 2004, 65, 635-648. [CrossRef]

5. Chisti, Y.; Yan, J. Energy from algae: Current status and future trends: Algal biofuels-A status report. Appl. Energ. 2011, 88, 3277-3279. [CrossRef]

6. Wijffels, R.H.; Barbosa, M.J. An outlook on microalgal biofuels. Science 2010, 329, 796-799. [CrossRef]

7. Lardon, L.; Hélias, A.; Sialve, B.; Steyer, J.-P.; Bernard, O. Life-cycle assessment of biodiesel production from microalgae. Environ. Sci. Technol. 2009, 43, 6475-6481. [CrossRef]

8. Gómez, C.; Escudero, R.; Morales, M.M.; Figueroa, F.L.; Fernández-Sevilla, J.M.; Acién, F.G. Use of secondary-treated wastewater for the production of Muriellopsis sp. Appl. Microbiol. Biot. 2013, 97, 2239-2249.

9. Cabanelas, I.T.D.; Ruiz, J.; Arbib, Z.; Chinalia, F.A.; Garrido-Pérez, C.; Rogalla, F.; Nascimento, I.A.; Perales, J.A. Comparing the use of different domestic wastewaters for coupling microalgal production and nutrient removal. Bioresour. Technol. 2013, 131, 429-436. [CrossRef] [PubMed]

10. Delrue, F.; Álvarez-Díaz, P.; Fon-Sing, S.; Fleury, G.; Sassi, J.-F. The environmental biorefinery: Using microalgae to remediate wastewater, a win-win paradigm. Energies 2016, 9, 132. [CrossRef]

11. Kumar, K.S.; Dahms, H.U.; Won, E.J.; Lee, J.S.; Shin, K.H. Microalgae-A promising tool for heavy metal remediation. Ecotox. Environ. Saf. 2015, 113, 329-352. [CrossRef] [PubMed]

12. Kousha, M.; Farhadian, O.; Dorafshan, S.; Soofiani, N.M.; Bhatnagar, A. Optimization of malachite green biosorption by green microalgae-Scenedesmus quadricauda and chlorella vulgaris: Application of response surface methodology. J. Taiwan Inst. Chem. Eng. 2013, 44, 291-294. [CrossRef]

13. Mata, T.M.; Martins, A.A.; Caetano, N.S. Microalgae for biodiesel production and other applications: A review. Renew. Sust. Energ. Rev. 2010, 14, 217-232. [CrossRef]

14. Farré, M.L.; Pérez, S.; Kantiani, L.; Barceló, D. Fate and toxicity of emerging pollutants, their metabolites and transformation products in the aquatic environment. TrAC-Trend. Anal. Chem. 2008, 27, 991-1007. [CrossRef]

15. Escapa, C.; Coimbra, R.N.; Paniagua, S.; García, A.I.; Otero, M. Comparative assessment of diclofenac removal from water by different microalgae strains. Algal Res. 2016, 18, 127-134. [CrossRef]

16. El-Bestawy, E. Treatment of mixed domestic-industrial wastewater using cyanobacteria. J. Ind. Microbiol. Biot. 2008, 35, 1503-1516. [CrossRef] [PubMed]

17. De Godos, I.; Muñoz, R.; Guieysse, B. Tetracycline removal during wastewater treatment in high-rate algal ponds. J. Hazard. Mater. 2012, 229-230, 446-449. [CrossRef] [PubMed]

18. Matamoros, V.; Gutiérrez, R.; Ferrer, I.; García, J.; Bayona, J.M. Capability of microalgae-based wastewater treatment systems to remove emerging organic contaminants: A pilot-scale study. J. Hazard. Mater. 2015, 288, 34-42. [CrossRef] [PubMed] 
19. De Wilt, A.; Butkovskyi, A.; Tuantet, K.; Leal, L.H.; Fernandes, T.V.; Langenhoff, A.; Zeeman, G. Micropollutant removal in an algal treatment system fed with source separated wastewater streams. J. Hazard. Mater. 2016, 304, 84-92. [CrossRef] [PubMed]

20. Martínez, L.; Otero, M.; Morán, A.; García, A.I. Selection of native freshwater microalgae and cyanobacteria for $\mathrm{CO}_{2}$ biofixation. Environ. Tech. 2013, 34, 3137-3143. [CrossRef] [PubMed]

21. Mann, J.E.; Myers, J. On pigments, growth, and photosynthesis of phaeodactylum tricornutum. J. Phycol. 1968, 4, 349-355. [CrossRef] [PubMed]

22. Langmuir, I. The adsorption of gases on plane surfaces of glass, mica and platinum. J. Am. Chem. Soc. 1918, 40, 1361-1403. [CrossRef]

23. Freundlich, H. Über die Adsorption in Lösungen. Z. Elktrochem. Angew. Phys. Chem. 1906, 57, 385-470.

24. Villaescusa, I.; Fiol, N.; Poch, J.; Bianchi, A.; Bazzicalupi, C. Mechanism of paracetamol removal by vegetable wastes: The contribution of $\pi-\pi$ interactions, hydrogen bonding and hydrophobic effect. Desalination 2011, 270, 135-142. [CrossRef]

25. Coimbra, R.N.; Calisto, V.; Ferreira, C.I.A.; Esteves, V.I.; Otero, M. Removal of pharmaceuticals from municipal wastewater by adsorption onto pyrolyzed pulp mill sludge. Arab. J. Chem. 2015. [CrossRef]

26. Marques, S.C.R.; Marcuzzo, J.M.; Baldan, M.R.; Mestre, A.S.; Carvalho, A.P. Pharmaceuticals removal by activated carbons: Role of morphology on cyclic thermal regeneration. Chem. Eng. J. 2017, 321, 233-244. [CrossRef]

27. Escapa, C.; Coimbra, R.N.; Paniagua, S.; García, A.I.; Otero, M. Nutrients and pharmaceuticals removal from wastewater by culture and harvesting of chlorella sorokiniana. Bioresour. Technol. 2015, 185, $276-284$. [CrossRef] [PubMed]

28. Escapa, C.; Coimbra, R.N.; Paniagua, S.; García, A.I.; Otero, M. Comparison of the culture and harvesting of chlorella vulgaris and tetradesmus obliquus for the removal of pharmaceuticals from water. J. Appl. Phycol. 2016. [CrossRef]

(C) 2017 by the authors. Licensee MDPI, Basel, Switzerland. This article is an open access article distributed under the terms and conditions of the Creative Commons Attribution (CC BY) license (http:/ / creativecommons.org/licenses/by/4.0/). 